\title{
Social Organization of Free-Ranging Ruffed Lemurs, Varecia variegata variegata: Mother-Adult Daughter Relationship
}

\author{
FRANCES J. WHITE, ANN S. BURTON, SUSAN BUCHHOLZ, AND \\ KENNETH E. GLANDER \\ Department of Biological Anthropology and Anatomy, Duke University, Durham, North \\ Carolina
}

The relationship between a mother and an adult daughter is examined in a group of free-ranging ruffed lemurs (Varecia variegata) at the Duke University Primate Center (DUPC). Although the two females were affiliative during the birth season, interactions during the mating season were predominantly agonistic. The maturing daughter was dominant to the mother, as has been observed in many caged social groups at the DUPC. Although both mother and daughter produced offspring in the same group, the daughter subsequently aggressively evicted the mother from the enclosure. It was not possible to maintain more than one long-term resident breeding female in the same social group. This pattern contrasts with observations of affiliation among breeding females in the wild.

(c) 1992 Wiley-Liss, Inc.

Key words: Varecia, social organization, dominance

\section{INTRODUCTION}

The social organization of ruffed lemurs is difficult to determine. Original descriptions of monogamous social structure in the wild [Tattersall, 1982; Petter et al., 1977] were confirmed by observations of captive animals [Klopfer \& Dugard, 1976; Kress et al., 1978; Klopfer \& Boskoff, 1979; Foerg, 1982]. When ruffed lemurs were released into a large enclosure at the Duke University Primate Center (DUPC), however, social behavior changed [Keith-Lucas \& Keith-Lucas, 1985]. The intolerance between mothers and mature daughters seen in smaller cages and outdoor runs [Foerg, 1982], was reduced so that both mothers and daughters bred, and larger group sizes became possible [Pereira et al., 1987; Pereira et al., 1988; White et al., 1989]. Observations in Madagascar of animals introduced onto a 500 ha island [Morland, 1990] have also reported larger group sizes. Observations in undisturbed, continuous rain forest in southeastern Madagascar have found both stable pairs and larger groups [White, 1989, 1991; Balko, pers. comm.]. When

Received for publication July 9, 1991; revision accepted April 24, 1992.

Address reprint requests to Frances J. White, Dept. of Biological Anthropology and Anatomy, Duke University, Durham, NC 27706. 


\section{2 / White et al.}

larger groups became possible in the enclosures at DUPC, however, ruffed lemurs did not form cohesive units [Keith-Lucas \& Keith-Lucas, 1985; Pereira et al., 1987, 1988; White et al., 1989].

Ruffed lemurs have a unique reproductive strategy. Unlike other mediumsized diurnal primates, ruffed lemurs give birth to litters rather than single offspring, build nests for the care of these infants, and carry the infants in their mouths [Petter, 1977; Foerg, 1982; Pereira et al., 1987, 1988].

Captive ruffed lemurs also show unusual dominance relationships among females as maturing daughters outrank their mothers under captive conditions [White, 1991; Alvarado, 1987; DUPC records]. In primate species with clear dominance hierarchies among females, younger females can outrank older females in groups with female transfer [for example, mantled howler, Alouatta palliata, Glander, 1980; Glander, in press; Clarke \& Glander, 1984]. In groups where both mothers and daughters regularly remain and breed, however, daughters usually assume a rank immediately below that of their mothers [Walters \& Seyfarth, 1987; but see Hrdy \& Hrdy, 1976]. Daughters sometimes outrank mothers in small groups [Chikazawa et al., 1979; Hausfater et al., 1982].

This paper presents data on the social organization and cohesion of a group of free-ranging ruffed lemurs at DUPC. The relationship between an adult daughter and her mother are examined during the birth season and the subsequent mating season to ascertain the impact of the changing dominance status of mother and daughter on group structure and whether this ruffed lemur group could sustain a long-term association of related, breeding females.

\section{METHODS}

The first matrilines of ruffed lemurs at the DUPC were established in 1962. Three ruffed lemur groups are currently maintained under free-ranging conditions in natural forest habitat enclosures. The study group was the first to be released (from 1983 to 1985 in Natural Habitat Enclosure 1 (NHE1) 0.59 ha, since June 17, 1985 in Natural Habitat Enclosure 2 (NHE2) 3.30 ha enclosure) and is the only ruffed lemur group currently containing an adult daughter. All individuals are identified by colored collars and pendants. The data was collected between February and May in NHE1 and October to December, 1985 in NHE2. The enclosure contained heated shelter boxes and several feeding stations for Purina monkey chow. Fresh fruit was provided daily and water was continually available. This diet was supplemented with foraging from the natural vegetation [Glander \& Rabin, 1983].

The original adult male and female (BA and $\mathrm{CA}$ ) were unrelated. They produced four male offspring (AO, born 1981; RE, born 1982; ER and PU, born 1984) and one female offspring (AM, born 1982). Both BA and AM gave birth in 1984, 1985 , and 1986. AM's infants from the first two years died. The rearing of AM's and BA's births in 1986 is described by Pereira et al. [1987].

The data presented are from a total of 141 hours of focal animal sampling (Altman, 1974). During the 1985 birth season 91 hours of data were collected for the mother (BA) and adult daughter (AM) and a further 50 hours were collected during the subsequent mating season (October to December) for all group members. These are supplemented with observations of expulsions and removals from the enclosure from DUPC records.

Aggressive and grooming interactions and five minute time points as nearest neighbor of each female with the other female versus with other group members were compared using G-tests of independence to determine if social relationships 
between the two females differed between birth and mating season. $G$ values are reported with Williams correction [Sokal \& Rohlf, 1981].

\section{RESULTS}

Both females were pregnant at the start of observation in February 1985. BA's litter, born during this study, consisted of 3 infants: males AC, ZU, and female CC. AM's 1985 infant died at birth from exposure. The deaths of AM's 1984 and 1985 infants were not caused by aggression from group members.

Agonistic interactions between mother (BA) and daughter (AM) were infrequent during the birth season with $\mathrm{BA}$ directing $8 \%$ of aggressive bouts towards AM (Fig. 1a) and AM directing 20\% of aggressive bouts toward BA (Fig. 1b). All but one of the agonistic interactions between the females occurred before AM gave birth on April 2, 1985. The remaining agonistic encounter occurred just before BA gave birth on April 24, 1985.

Affiliation between the females increased after the births. BA and AM were frequent nearest neighbors and grooming partners (Fig. 1b,c).

BA separated herself from the rest of the group for approximately two weeks after giving birth. During this time, both her mate (CA) and her son (AO) guarded BA's infants whenever BA was away from the nest. Upon rejoining the group, BA and CA aggressively expelled their son RE from the enclosure.

During the following mating season (October to December), affiliation between BA and AM changed (Fig. 1c,d). The frequency of aggression directed by each female towards the other relative to that directed at other group members was not significantly dependent on the season (for BA, G $=0.013$, df $=1$, ns; AM, G = $0.421, \mathrm{df}=1$, ns). The frequency of nearest neighbor association was dependent on season for both BA (G $=54.386, \mathrm{df}=1, P<0.001)$ and $\mathrm{AM}(\mathrm{G}=24.426, \mathrm{df}=1$, $P<0.001)$. The two females rarely associated with each other during the mating season. BA's mate CA was most often the nearest neighbor of both females. Grooming was significantly dependent on the season (for $\mathrm{BA}, \mathrm{G}=13.429$, $\mathrm{df}=1, P<$ $0.001 ; \mathrm{AM}, \mathrm{G}=11.992, \mathrm{df}=1, P<0.001$ ). There were no grooming interactions between the two females during the mating season. Each received aggression from the other (AM received 1 bout, BA received 23 bouts). AM was clearly dominant in overt interactions and BA would chatter submissively when AM approached within $3 \mathrm{~m}$ of her. No other group member directed aggression toward either female.

Agonistic interactions between the females began approximately three weeks prior to AM's peak estrus period and continued until after BA's estrus period. The predominant agonistic interaction consisted of AM chasing her father (CA) away from BA and slapping BA. Gradually AM's aggression toward BA increased until she repeatedly attached BA whether or not CA was present. BA consistently chattered in submission whenever her daughter approached.

During the mating season, $\mathrm{CA}$ was aggressive towards his adult son, $\mathrm{AO}$, and would chase him away whenever $\mathrm{AO}$ approached the females. During peak estrus (approximately 4-8 hours), CA was extremely aggressive toward both his sons AO and ER, and prevented them from attempting to copulate. CA copulated 13 times with his daughter AM during a two-day period. At the end of this time, her brother AO was able to approach and successfully copulate with AM.

AM gave birth on March 16, 1986 and BA on April 8, 1986 [Pereira et al., 1987]. The females built nests in opposite ends of the enclosure and both remained separate from the group for about two weeks. Three weeks after the birth of BA's infants, the females parked their infants together and guarded and nursed both 
284 / White et al.
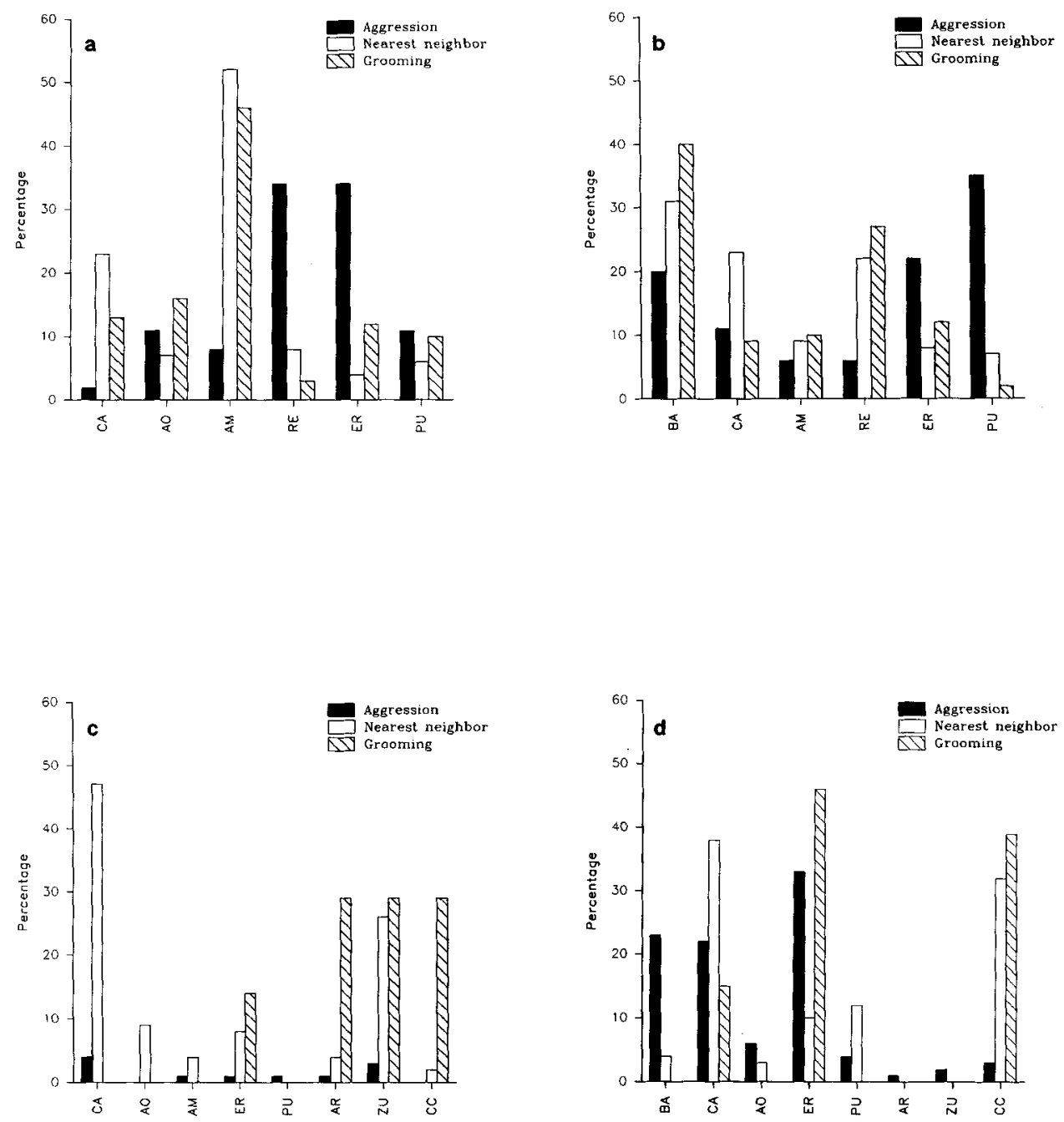

Fig. 1. a: Interactions by BA during the birth season ( $n=38$ aggression given, $n=84$ nearest neighbor, $n=$ 61 grooming bouts: 41.5 hours of focal animal sampling on BA). b: Interactions by AM during the birth season $(n=46$ aggression given, $n=133$ nearest neighbor, $n=101$ grooming bouts: 49.5 hours of focal animal sampling on $A M$ ). c: Interactions by BA during the mating season ( $n=11$ aggression given, $n=53$ nearest neighbor, $n=7$ grooming bouts: 50 hours observation of all interactions by group members). d: Interactions by AM during the mating season ( $n=94$ aggression given, $n=73$ nearest neighbor, $n=13$ grooming bouts: 50 hours observation of all interactions by group members).

infants. When BA returned to the group, she and her mate CA aggressively evicted their son ER from the enclosure.

After weaning her infant in the fall of 1986, AM successfully ejected both her mother BA and her maturing sister CC from the enclosure by chasing them several times over the electrified fence surrounding the enclosures. Although attempts were made to reintroduce BA back into the enclosure, each time aggression from AM prevented BA from reintegrating into the group. Finally AM and her son, VO, were removed from the group and BA was able to reestablish her position as dominant female. 


\section{DISCUSSION}

When captive ruffed lemurs were first moved to large enclosures, the intolerance between mother and maturing daughter seen in cages was initially reduced. Mother and daughter remained in the group for two years past the daughter's first estrus. The daughter mated with her father and gave birth to two offspring that did not survive. Ruffed lemur first births at DUPC are unsuccessful. Even first infants removed and hand raised do not survive. These births occur when females are 18 months of age. The age of females at first birth, and the survivability of first infants, is not currently known for wild studies, but these first births in captivity may represent accelerated maturation associated with captive conditions.

The relationship between mother and adult daughter was not consistent through the year. While pregnant and just after giving birth, the two females associated with each other and AM groomed BA's infants. In contrast, during the mating season there was aggression and little affiliation. Based on both consistent direction of interactions and on AM's ability to supplant her mother BA from food, AM was dominant to $\mathrm{BA}$. This dominance relationship between the two females was most apparent during the mating season. Female-female affiliation was most obvious during the birth season.

During the mating season, the dominant female attempted to restrict the access of the dominant male to the subordinate female. As guarding of infants by the male may be an important factor in determining infant survivability, the dominant female may attempt to prevent males from investing in other offspring, or to increase the time between the estrus periods of the females.

The estrus periods of the two females were three weeks apart and the females constructed their nests at opposite ends of the enclosure. The infants remained in the nest for about 2 to 3 weeks. This asynchrony in estrus periods allowed the male to guard the nests in sequence, but the male could not guard the infants of the dominant female after they left their nest. Only after the infants of the second female left the nest could the two sets of infants be parked together and guarded at the same time. If the estrus periods of the two females had been synchronous, the births would have been simultaneous and one of the nests would not have been guarded by the male.

Following the daughter's third, but first successful, mating season, all affiliation between the females ceased and the daughter aggressively evicted the mother from the social group. The eviction of subordinates by a dominant female resulted in there being only one long-term resident successfully breeding male and female in the group.

The data presented here are more consistent with a single-female social system than with a multi-female social group based on related females. This is, however, only a single test of the ability of a mature daughter to remain in the group. This social situation is now being repeated with a second maturing daughter in the group. If mothers leave and daughters remain to breed in natal territories in the wild, mothers may transfer into other groups and either the levels of inbreeding are high or daughters have access to unrelated males. Ruffed lemurs may, therefore, show both male and female transfer in the wild.

\section{CONCLUSIONS}

1. Affiliative interactions between a female ruffed lemur and her adult daughter were present during the birth season but not during the mating season.

2. The social organization of ruffed lemurs is apparently characterized by 
286 / White et al.

daughters that outrank their mothers on reaching maturity at DUPC. The daughter in the enclosure ejected the mother from the social group.

3. It was not possible to maintain more than one related, long-term resident breeding female in the social group at DUPC.

\section{ACKNOWLEDGMENTS}

We thank Elwyn Simons, Patricia Feeser, Claire Hemingway, Patricia Wright, Carel van Schaik, and Michael Pereira for assistance and stimulating discussions. This is Duke University Primate Center publication No. 521.

\section{REFERENCES}

Altmann, J. Observational study of behavior: Sampling methods. BEHAVIOUR 49: 227-267, 1974.

Alvarado, L. 1987. Female Dominance Patterns in Ruffed Lemurs. Student Paper, DUPC records.

Chikazawa, D.; Gordon, T.; Bean, C; Bernstein, I. Mother-daughter dominance reversals in rhesus monkeys. PRIMATES 20: 301-305, 1979.

Clarke, M.R.; Glander, K.E. Female reproductive success in a group of free-ranging howling monkeys (Alouatta palliata) in Costa Rica. Pp 111-126 in FEMALE PRIMATES: STUDIES BY WOMEN PRIMATOLOGISTS. M. Small ed. New York, Alan R. Liss, 1984.

Foerg, R. Reproductive behavior in Varecia variegata. FOLIA PRIMATOLOGICA 38: 108-121, 1982.

Glander, K.E. Reproduction and population growth in free-ranging mantled howling monkeys. AMERICAN JOURNAL OF PHYSICAL ANTHROPOLOGY 53:25-36, 1980.

Glander, K.E. Group composition in mantled howling monkeys. AMERICAN JOURNAL OF PHYSICAL ANTHROPOLOGY 63:163, 1984.

Glander, K.E. Primate Diets: Physiological and behavioral features. In THE CAMBRIDGE ENCYCLOPEDIA OF THE HUMAN SPECIES. R.D. Martin, D. Pilbeam, S. Jones eds. Cambridge, Cambridge University Press, in press.

Glander, K.E.; Rabin, D.P. Food choice from endemic North Carolina tree species by captive prosimians (Lemur fulvus). AMERICAN JOURNAL OF PRIMATOLOGY 5: 221-229, 1983.

Hausfater, G.; Altmann, J.; Altmann, S. Long-term consistency of dominance relations in female baboons (Papio cynocephalus). SCIENCE 217:752-755, 1982.

Hrdy, S.B.; Hrdy, D.B. Hierarchical relations among female hanuman langurs (Primates: Colobinae, Presbytis entellus). SCIENCE 193:913-915, 1976.

Keith-Lucas, T.; Keith-Lucas, L. From covered run to natural habitat enclosure:
Changes in behavior in a ruffed lemur troop. Paper presented at the Seventh Annual Meeting of the American Society of Primatologists, 1985.

Klopfer, P.H.; Boskoff, K. Maternal behavior in prosimians. Pp 123-157 in THE STUDY OF PROSIMIANS. G.A. Doyle and R.D. Martin eds. New York, Academic Press, 1979.

Klopfer, P.H.; Dugard, J. Patterns of maternal care in lemurs III: Lemur variegatus. ZEITSCHRIFTE FÜR TIERPSYCHOLOGIE 40:210-220, 1976.

Kress, J.H.; Conley, J.M.; Eaglen, R.H.; Ibanez, A.E. The behavior of Lemur variegatus, Kerr 1792. ZEITSCHRIFTE FUR TIERPSYCHOLOGIE 48:87-99, 1978.

Morland, H.S. Parental behavior and infant development in ruffed lemurs (Varecia variegata) in a northeast Madagascar rain forest. AMERICAN JOURNAL OF PRIMATOLOGY 20:253-265, 1990.

Pereira, M.E.; Klepper, A.; Simons, E.L. Tactics of care for young infants by forestliving ruffed lemurs (Varecia variegata variegata): Ground nests, parking, and biparental guarding. AMERICAN JOURNAL OF PRIMATOLOGY 13:129-144, 1987.

Pereira, M.E.; Sieligson, M.A.; Macedonia, J.M. The behavioral repertoire of the black-and-white ruffed lemur, Varecia variegata variegata. FOLIA PRIMATOLOGICA 51:1-31, 1988.

Petter, J.J.; Albignac, R.; Rumpler, Y. FAUNE DE MADAGASCAR, VOL. 44: MAMMIFERES LEMURIENS. Paris, ORSTOM, CNRS, 1977.

Sokal, R.R.; Rohlf, F.J. BIOMETRY, SECOND EDITION. New York, Freeman and Company, 1981.

Tattersall, I. THE PRIMATES OF MADAGASCAR. New York, Columbia University Press, 1982.

Walters, J.R.; Seyfarth, R.M. Conflict and Cooperation. Pp 306-317 in PRIMATE SOCIETIES. B. Smuts; D.L. Cheney; R.M. Seyfarth, R.W. Wrangham, T.T. Struhsaker eds. Chicago, The University of Chicago Press, 1987. 
White, F.J. Diet, ranging behavior and social organization of the black and white ruffed lemur, Varecia variegata variegata, in southeastern Madagascar. AMERICAN JOURNAL OF PRIMATOLOGY 78(2): 323, 1989.

White, F.J. Social organization, feeding ecology and reproductive strategy of ruffed lemurs, Varecia variegata. Pp 81-84 in Primatology Today: Proceedings of the XIII Congress of the International Primatolog- ical Society, Nagoya and Kyoto 18-24 July, 1990. A. Ehara, T. Kimura, O. Takenaka, M. Iwamoto eds. Amsterdam, Elsevier Science Publishers, 1991.

White, F.J.; Burton, A.; Buchholz, S.; Glander, K.E. Social organization, social cohesion and group size of wild and captive black and white ruffed lemurs. AMERICAN JOURNAL OF PRIMATOLOGY 18(2):170, 1989 